\title{
Букина Т.Г. \\ Православный художественный текст как средство воспитания религиозной толерантности на занятиях по русскому языку как иностранному
}

Уральский юридический институт МВД России

(Россия, Екатеринбург)

doi: 10.18411/trnio-11-2021-142

\section{Аннотация}

В статье описывается опыт преподавания русского языка как иностранного с позиций приобщения иностранных обучающихся к русской духовной культуре в целях воспитания в них религиозной толерантности. Работа основана на теоретическом и практическом материале, накопленном автором за период преподавания дисциплины в Уральском юридическом институте МВД России. В статье представлены рекомендуемые для изучения темы, а также описаны приемы работы с текстом из книги И.С. Шмелева «Лето Господне», который знакомит иностранных обучающихся с бытом и представлениями о духовности русской православной семьи рубежа XIX - XX веков. Данная повесть является ценным учебным материалом ввиду своего богатого духовного содержания, отражающего нравственные ценности русского национального сознания.

Ключевые слова: русский язык как иностранный, религиозная толерантность, русская духовная культура, константы русской культуры, приемы работы с текстом.

\section{Abstract}

The article describes the experience of teaching Russian as a foreign language from the standpoint of familiarizing foreign students with Russian spiritual culture in order to foster religious tolerance in them. The work is based on theoretical and practical material accumulated by the author during the period of teaching the discipline at the Ural Law Institute of the Ministry of Internal Affairs of Russia. The article presents recommended topics for study, as well as describes the methods of working with the text of the story of I. Shmelev "Summer of the Lord", which acquaints foreign students with the life and ideas about the spirituality of the Russian Orthodox family at the turn of the XIX - XX centuries. This story is a valuable educational material due to its rich spiritual content, reflecting the moral values of the Russian patriarchal consciousness.

Keywords: Russian as a foreign language, religious tolerance, Russian spiritual culture, constants of Russian culture, methods of working with text.

Для иностранных граждан обучение в российском вузе - качественно новый этап в жизни, связанный с изучением русского языка как главного средства коммуникации, с познанием национальной культуры, ее проявлений в образе и стиле жизни россиян, а также историко-культурной памяти народа.

С первых дней пребывания в России у иностранных обучающихся начинается сложный процесс адаптации к новой для них действительности. Поэтому на начальном этапе преподавания языка особую актуальность приобретает обучение полноценной коммуникации на русском языке, целью которого является формирование коммуникативной компетенции. Коммуникативная компетенция - «способность обучаемого к восприятию любых высказываний и готовность к созданию своих речевых произведений в соответствии со знаниями, умениями, практическим опытом, принятыми нормами языка, личностными качествами, с использованием невербальных средств, а также умение ориентироваться в пространстве, обстановке, учитывая тему, цель, задачи, коммуникативные и этические установки; достигать результатов посредством речи» [4: с. 28].

Иностранные обучающиеся в вузах МВД - представители разных этнических групп и вероисповеданий. Как правило, в силу выбора своей будущей профессии (защитники правопорядка) это люди, вполне терпимо относящиеся к чужой культуре и традициям. При 
этом естественно, что, получая образование в чужой стране, нельзя не изучать быт, нравы и культуру этой страны.

Как отмечает В.Э. Матвеенко, «в настоящее время одной из актуальных и сложных проблем, с которой сталкиваются преподаватели русского языка как иностранного, является дезинформированность - наличие «мифов» у студентов-иностранцев о нашей стране, истории и культуре, народе и традициях. <..> В связи с этим практический курс русского языка, включающий в себя академические аспекты - грамматику, фонетику, аудирование, развитие речи и т.д. - неотделим от другой сложной и немаловажной задачи, стоящей перед преподавателем: развенчания «мифов» о России и знакомство студентов с русскими традициями и культурой, работа над приобщением обучающихся к духовной культуре России на каждом занятии по русскому языку» [1: с. 12-13].

Текст, в том числе художественный, в процессе изучения русского языка - это главный учебный материал. Как правило, работа с текстом подразумевает развитие навыков чтения, аудирования, перевода, анализа, рассуждения, практического воспроизведения (устный пересказ, изложение). Такая работа позволяет расширить словарный запас. При разработке планов практических занятий тексты для чтения и обсуждения, а также для изучения грамматики и лексики объединяются в темы: «Я. Мир вокруг меня», «Знакомство», «Мой дом. Моя семья. Мои друзья», «Улица. Транспрт. Магазин», «Кухня народов России. Поход в ресторан», «Россия: географическое положение, природа, климат, население, достопримечательности», «Культура России: история и современность» и т.д. [3] В каждой из этих тем обязательно находится место для обсуждения нравственных ценностей русского народа, для анализа традиций. Обязательно в ходе обсуждения текста на какую-либо из указанных тем обучающимся предлагается сравнить традиции и обычаи России и традиции родной страны.

Как показывает практика, понимание констант русской культуры облегчается, когда иностранные обучающиеся узнают в новой для них действительности отголоски своей культуры, параллели со своими национальными традициями. В рамках данной статьи мы обратимся к традициям христианской православной культуры. При этом, говоря о христианстве, мы не обращаемся к официальной форме религиозной жизни, установленной русской православной церковью. В нашем случае речь именно идет о народной культуре, рожденной в лоне православного сознания, «инвариантное содержание которой составляют представления о природе, человеке, об идеалах мудрости, добра, красоты, о формах «правильного и неправильного» образа жизни, поведения в обществе, о служении людям, способах воспитания» [2: с. 90]

Так, например, во всех культурах есть понятие Пост. У мусульман (обучающихся из государств Средней Азии) это Рамадан, или Рамазан - священный месяц; у буддистов (в Монголии буддизм - одна из основных религий) - это Васса, Дождевой, или Буддийский, пост. При всей разнице ритуальной составляющей внешнее проявление поста - это или полный, или частичный отказ от пищи. В каждой культуре верующие поддерживают свой организм разными способами. На примере отрывков из книги И.С. Шмелева «Лето Господне» иностранные обучающиеся на дисциплине «Русский язык как иностранный» узнают о гастрономической составляющей Великого православного Поста. Цель текста - не только познакомить иностранных слушателей с новыми словами по теме «Русская народная кухня» или, например, с активными словообразовательными моделями, но и привить уважительное отношение к ведущей религии страны, в которой они получают образование.

«Какой же великий торг!

Широкие плетушки на санях, - все клюква, клюква, все красное. Ссылают в щепные короба и в ведра, тащзат на головах.

- Самопервеющая клюква! Архангельская клюковка!..

- Клю-ква... - говорит Антон, - а по-нашему и вовсе журавиха.

И синяя морошка, и черника - на постные пироги и кисели. А вон брусника, в ней яблочки. Сколько же брусники! < ... 
A вот капуста. Широкие кади на санях, кислый и вонький дух. Золотится от солнышка, сочнеет. Валят ее в ведерки и в ушаты, гребут горстями, похрустьвают - не горчит ли? $\mathrm{Mbl}$ пробуем капустку, хоть нам не надо. Огородник с Крымка сует мне беленькую кочерыжку, зимнииу, — «как сахар!». Откусишь - щелкнет.

А вот и огуриами потянуло, крепким и свежим духом, укропным, хренным. Играют золотые огуриы в рассоле, пляшут. Вылавливают их ковшами, с палками укропа, с листом смородинным, с дубовым, с хренком. Антон дает мне тонкий, крепкий, с пупырками; хрустит мне в ухо, дышит огуриом. <.. >

А вот вороха морковки - на пироги с лучком, и лук, и репа, и свекла, кроваво-сахарная, как арбуз. Кадки соленого арбуза, под капусткой поблескивает зеленой плешкой.

- Редька-то, гляди, Панкратыч... чисто боровки! Хлебца с такой умнешь!

-И две умнешь, - смеется Горкин, забирая редьки. А вон - соленье; антоновка, морошка, крыюжовник, румяная брусничка с белью, слива в кадках... Квас всякий - хлебный, кислощейный, солодовый, бражный, давний - с имбирем...<..>

A вот и медовый ряд. Пахнет иерковно, воском. Малиновый, золотистый, показывает Горкин, - этот называется печатный, энтот - стеклый, спускной... а который темный - с гречишки, а то господский светльйи, липнячок-подсед. < .. >

A вот - варенье. А там - стопками ледяных тарелок - великопостный сахар, похожий на лед, зеленый, и розовый, и красный, и лимонный. А вон-чернослив моченый, $u$ винная ягода на вязках, и бурачки абрикоса с листиком, сахарная кунжутка, обсахаренная малинка и рябинка, синий изюм кувиинный, самонастояще постный, бруски помадки с елочками в желе, масляная халва, калужское тесто кулебякой, белевская пастила... $u$ пряники, пряники - нет конца» [5: с. 307-308].

Справедливости ради следует заметить, что и современное поколение обучающихся российских вузов вряд ли имеет полное представление об описанных реалиях столетней давности. Трудности возникнут прежде всего в понимании диалектных названий клюквы (журавиха) или капусты (зимница). Для нас же здесь важно познакомить иностранцев с новыми понятиями, которые в их стране отсутствуют, но которые являются неотъемлемой составляющей образа России. С помощью данного отрывка иностранные обучающиеся узнают не только о понятии «постный рынок», но и пополняют свой словарный запас путем знакомства с названиями таких ягод, как клюква, морошка, черника, брусника, которые в их странах скорее всего являются экзотизмами.

Для общего понимания текста с обучающимися можно обсудить следующие вопросы: какие ягоды можно купить на базаре? В каком виде? Что можно приготовить из ягод? Какие овощи продаются на постном рынке? Перечислите названия емкостей, в которых хранятся ягоды и овощи. Какой национальный напиток можно купить на постном рынке?

Видеоряд, как правило, способствует оптимизации усвоения материала, поэтому параллельно с чтением текста можно показать ролик с чтением этого отрывка отечественными артистами.

Обучающиеся обычно активно включаются в работу по изучению новых понятий. Они начинают рассказывать, какие постные продукты можно купить на рынке их страны и какие блюда готовят верующие во время поста. На этом этапе занятия можно порассуждать о параллелях русской постной кухни и постной кухни их страны. Как правило, в конце таких занятий обучающиеся приходят к выводу, что, как бы ни были далеки наши страны друг от друга, как бы ни различались они по ландшафту, природе, погодным условиям, вероисповеданию, очень много общего можно найти в традициях и быте наших народов. Именно через такое понимание иностранные обучающиеся приходят к религиозной толерантности.

Таким образом, аудиторная работа по русскому языку в группах иностранных обучающихся заключается не только в достижении практической цели - научить курсантов говорить по-русски, объяснить грамматику, пополнить словарный запас и др., - но и в расширении их знаний о России, русской культуре, о православии как ведущей религии 
нашего государства за счет включения в обучение текстов и фильмов культурологического и просветительского содержания.

$* * *$

1. Матвеенко В.Э. Формирование знаний о духовных ценностях русского общества на занятиях с иностранными студентами / В.Э. Матвеенко // Санкт-Петербургский образовательный вестник. - 2019, № 1(29). - с. 11-16.

2. Мащенко С.П. Дидактический потенциал «народного православия» в обучении русскому языку как иностранному / С.П. Мащенко // Вестник ТГПУ. - 2005. Выпуск 3 (47). Серия: гуманитарные науки (филология). - С. $90-95$

3. Русский язык как иностранный : учебник и практикум для вузов / Н. Д. Афанасьева, М. В. Беляков, И. Б. Могилева [и др.] ; ред. Н. Д. Афанасьева. - Москва : Юрайт, 2020. - 352 с.

4. Стурикова М.В. Коммуникативная компетенция: к вопросу о дефиниции и структуре / М.В. Стурикова // Инновационные проекты и программы в образовании. - 2015, № 6. - С. 28.

5. Шмелев И.С. Избранное / И.С. Шмелев. - Москва: издательство «Правда», 1989. - 688 с.

\section{Вакуленко О.В., Пельменщикова Е.В. \\ Опыт организации волонтерской деятельности детей и молодежи в учреждениях дополнительного образования}

ФГБОУ ВО «Шадринский государственный педагогический университет»

(Россия, Шадринск)

doi: 10.18411/trnio-11-2021-143

\section{Аннотация}

В статье рассматриваются вопросы деятельности волонтерских объединений в системе дополнительного образования детей. Проанализирован опыт организации волонтерских объединений в учреждениях дополнительного образования. Определены проблемы в организации волонтерской деятельности в учреждениях дополнительного образования детей и молодежи.

Ключевые слова: учреждения дополнительного образования, детские и молодежные общественные объединения, педагогический потенциал волонтерской деятельности.

\section{Abstract}

The article discusses the issues of the activities of volunteer associations in the system of additional education for children. The experience of organising volunteer associations in institutions additional education was analysed. Problems in the organisation of volunteer work in institutions of additional education for children and young people were identified.

Keywords: institutions of additional education, children's and youth public associations, pedagogical potential of volunteer activity.

Развитие современной молодежи происходит в сложных условиях, которые обусловлены коренными переменами во всех сферах общественной жизни России. Многочисленные проблемы в стране - агрессия, преступность, финансовая нестабильность, безработица, отсутствие досуга увеличивают у молодого поколения неуверенность в завтрашнем дне. Пропадает интерес к знаниям и труду, появляется склонность к негативным формам инициативы и предпринимательства. Эти изменения в ценностных ориентациях молодежи свидетельствуют об ухудшении нравственного здоровья общества. И в тоже время молодость - это период формирования взглядов и убеждений, профессионального и личностного самоопределения, начало трудовой карьеры и создания семьи. Помогают избежать нравственного разрушения общественные институты воспитания, такие как детскомолодежные объединения, которые не могут заменить школа и семья.

В условиях современной ситуации общественного развития важнейшим средством воспитания детей и молодежи, по нашему мнению, могут выступать именно детские и 